\title{
CUATRO ESTACIONES EN LA HABANA: DE LA LITERATURA AL CINE, DEL CINE A LA TELEVISIÓN
}

\author{
Paula GARCÍA TALAVÁN \\ Universidad Alfonso X El Sabio \\ talavanpaula@hotmail.com \\ La maldita circunstancia del agua por todas partes \\ me obliga a sentarme en la mesa del café. \\ Virgilio Piñera
}

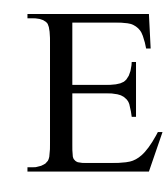

1 prejuicio elitista que proclamaba la superioridad de la literatura frente al cine parece superado hoy que este ha pasado a ser valorado positivamente frente a la televisión; y que, incluso, la ficción televisiva es más apreciada desde un punto de vista cultural que, por ejemplo, el videojuego. Sin embargo, se sigue discutiendo sobre la superioridad de unos medios sobre otros cuando, tal y como propone José Antonio Pérez Bowie, al referirnos a las prácticas adaptativas en el actual panorama cultural, resulta más adecuado hablar de una transferencia de materiales ficcionales entre los distintos medios que del valor o de la primacía de uno sobre los demás. Efectivamente, la ficción se ha convertido en la fuente principal de la que se nutre el mercado del entretenimiento, «y la necesidad de la industria de proporcionar constantemente nuevos contenidos hace que el reciclaje de materiales ficcionales y su intercambio entre los distintos soportes sea una práctica común» (2010: 22).

Esto se hace evidente si pensamos en las narrativas transmedia, tan de moda en la actualidad; esto es, en los relatos que se extienden a través de múltiples medios (Scolari, 2013: 45): libros, películas, obras de teatro, series de televisión, series en la red, cómics, videojuegos, etc. Una de las razones fundamentales de este trasvase de elementos es el beneficio mercantil que genera, ya que con este ejercicio se trata de «poner en circulación materiales que ya han demostrado su eficacia» (Pérez Bowie, 2010: 22). Eso es lo que hace el director español Félix Viscarret al llevar, primero, al cine y, después, a la televisión la tetralogía novelesca «Las cuatro estaciones» de Leonardo Padura, traducida, al menos, a diecisiete idiomas.

Las novelas que adapta Viscarret, las cuatro primeras de un ciclo de ocho, se escribieron entre 1991 y 1998, y se localizan en La Habana, en las cuatro estaciones del año 1989, aunque la mentalidad y la perspectiva de los personajes es la de quienes ya tienen la experiencia de la gran crisis económica 
y social vivida en Cuba en la primera mitad de década de los noventa. La película -Vientos de La Habana (2016)-, está basada en la segunda novela -Vientos de Cuaresma (1994)-, que transcurre en primavera. Esta se transforma después en uno de los cuatro capítulos que componen la miniserie Cuatro estaciones en La Habana (2016), y que se dividen, a su vez, en dos partes de 45 minutos de duración cada una de ellas. El primer capítulo lleva el título de la película, y los otros tres, el mismo título que las novelas Pasado perfecto, Máscaras y Paisaje de otoño. La adaptación audiovisual procura ser fiel al texto original e intenta trasladar el complejo mundo de Conde -con su vida policial, con su vida íntima con los amigos y con sus aspiraciones de ser escritor-a la pantalla. Su punto fuerte es la ambientación propia del cine negro que consigue dar a la luminosa, colorida y bulliciosa ciudad de La Habana; lo que permite, como es deseo del director, situar su obra en la novedosa tendencia del «noir caribeño».

Es importante señalar que las novelas de Padura tienen un claro componente cinematográfico, no solamente porque están llenas de referencias a películas, actores y personajes de cine, sino porque, además, algunos pasajes tienen un efecto fílmico muy particular: parecen directamente extraídos de una película. Dicho efecto viene dado, en mi opinión, por la fragmentación narrativa que nos hace saltar inmediatamente de un escenario a otro, por la descripción detallada de los ambientes y de los espacios por los que transita el protagonista, por la abundante adjetivación utilizada, por la atención que se presta a los colores y a los contrastes lumínicos, reproducidos en el texto literario, y por la música que, como la banda sonora de una película, acompaña en ciertos momentos las acciones de los personajes. Esta idea la confirman hoy tanto el director de las adaptaciones cinematográficas como Lucía López Coll, coguionista de la película y de la miniserie. Como señala López Coll con motivo de la presentación de la película en la Casa de América de Madrid, las novelas de Padura son tan cinematográficas que es muy fácil para el lector ir recreando las imágenes de lo que Conde ve o de lo que pasa por su mente; es decir, puede imaginar fácilmente todo un mundo en torno a este personaje. Esto no significa, como pensó en un principio, que su adaptación al medio cinematográfico o televisivo fuera sencilla, ya que Conde es un personaje bastante complejo, que tiende más a la reflexión que a la acción (Padura, 2016); y en estas novelas todo ocurre en la cabeza de Conde, lo que dificulta sobremanera la transformación a ese otro lenguaje en el que priman los diálogos y lo visual.

Las novelas, aunque son policiales porque contienen rasgos que permiten identificarlas como tales - cuentan con un investigador, con algunos crímenes y, cuestión fundamental, con una investigación como hilo conductor de la trama ${ }^{1}$, no tienen como objetivo la resolución de un enigma; su intención principal es la de escrutar con ojo crítico la realidad cubana contemporánea y la de repasar desde un punto de vista disconforme la historia oficial de Cuba de las últimas décadas. Coincidiendo con el tipo de policial que viene haciéndose desde mediados de los setenta en los países iberoamericanos, identificado como «neopolicial», las novelas de Padura muestran una preocupación máxima por la cuestión estética: son novelas muy trabajadas desde el punto de vista artístico, y son claramente autorreflexivas y autoconscientes.

\footnotetext{
${ }^{1}$ Este último es, según José Colmeiro, el único rasgo distintivo de toda novela policial (1994: 55).
} 
Dada la dificultad que entraña traducir los procesos mentales de Conde -con todas sus reflexiones sobre el pasado, el presente y el futuro del país y de su propia generación- al lenguaje cinematográfico, en este trabajo me interesa averiguar, por un lado, qué tipo de adaptación hace Viscarret para lograr un nuevo producto coherente y funcional en el medio audiovisual, qué aspectos decide potenciar y de cuáles prescinde. Por otro lado, trataré de analizar la poeticidad de una película y de una miniserie que adaptan unas novelas no solamente muy cinematográficas sino también profundamente literarias. Para ello, tendré en cuenta, primero,el lugar que en estas ocupan la literatura y la reflexión metaficcional; a continuación, abordaré la visualidad, particularmente, de la miniserie, sobre todo en lo que concierne a la representación de La Habana, ya que «la visualidad en sí misma, es decir las dimensiones de su plasticidad y su poeticidad, claramente diferenciables tanto de los contenidos temáticos del filme como de su narratividad o su estatuto de ficción, [son] las magnitudes que más lo aproximan a la literatura» (Pérez Bowie, 2008: 26).

\section{Cuatro estaciones en La Habana: reescritura}

Apoyándose en aportaciones previas de autores como Thierry Groensteen, Robert Stam y Michel Serceau, entre otros, Pérez Bowie propone concebir la adaptación como reescritura; es decir, como un proceso de apropiación y de revisión de un texto previo con el objeto de transformarlo u observarlo desde un nuevo punto de vista, o de trasponerlo a un nuevo contexto. Dependiendo de la postura que se adopte con respecto al modelo, el resultado puede ser un homenaje, un cuestionamiento crítico, una parodia, un diálogo con el precedente para profundizar en el subtexto o la simple vulgarización (2010: 27-28). En cualquier caso, la reescritura de un texto literario para presentarlo en un medio audiovisual siempre implica una transformación porque es necesario recurrir al lenguaje de otras artes y medios de expresión -teatro, pintura, música, comic, televisión, etc.- para constituir uno propio.

Para valorar el trabajo realizado por Viscarret, creo necesario tener en cuenta que el autor de las novelas, Padura, participa también en el proceso de adaptación al medio audiovisual construyendo, junto a López Coll, el guion. No obstante, como ha reconocido el propio Padura en la entrevista antes citada, el grueso del trabajo recayó sobre López Coll, que se ocupó de crear la estructura del guion y de introducir nuevas líneas narrativas; su participación fue solo secundaria. Esto fue así por decisión propia, ya que le incomoda tener que someter su trabajo a los dictados del director y del productor, que son, en definitiva, quienes tienen la última palabra (Padura, 2016). Por tanto, no podemos hablar estrictamente de una autoadaptación: el autor no es exactamente el mismo.

En cuanto al contexto en el que se hace la adaptación audiovisual, hay que señalar que este varía, aunque no demasiado. Desde que apareció la última novela de la tetralogía en 1998 hasta la fecha en la que se ha presentado la película -septiembre de 2016 en el Festival de San Sebastián- y en la que se ha emitido la miniserie -diciembre de 2016 en Netflix y enero de 2017 en Movistar Plus-, han transcurrido casi veinte años. En ese tiempo, Cuba ha cambiado bastante: se ha legalizado el trabajo por cuenta propia, se ha relajado el control en materia de viajes, preferencias sexuales, religiosas, 
musicales y artísticas, el país se ha abierto a la inversión extranjera y ha visto crecer, sobre todo en los últimos años, las diferencias sociales entre la población. La perspectiva sobre la realidad que ahora tienen los cubanos, después de la caída del Muro de Berlín, y después de la crisis del Periodo Especial, también ha cambiado. Ahora ven con más distancia, con mucha más información y desde un punto de vista mucho más crítico, el proceso revolucionario y sus numerosísimas exigencias. El interés que, para ellos, tiene la obra de Padura, y que, supongo, esperan encontrar también en la de Viscarret, es que ofrece un minucioso análisis de su propia realidad, desde la perspectiva de un personaje complejo, que pertenece a la generación de quienes nacieron y se educaron en la Revolución, y ahora experimenta un profundo desencanto, vistos los resultados.

Sobre el guion hay que decir que, en él, se suprimen personajes, sucesos y otros elementos de la narración original -por ejemplo, no aparece recreado el pasado de juventud de Conde, que es parte importante en las novelas porque ayuda a entender la situación del presente; ni la profunda reflexión que este hace sobre el trabajo del policía o sobre cuestiones relacionadas con el momento histórico que le ha tocado vivir, como son la responsabilidad, el sacrificio y la culpa-. Además, se condensan los diálogos y, como señala Viscarret, se da preferencia a los momentos relacionados con la investigación del crimen y con la vida íntima de Conde; esto es, a la relación con sus amigos y a sus relaciones sentimentales (Padura, 2016). Para que el nuevo texto funcione, se añaden personajes y líneas narrativas; es el caso de El Jardinero, jefe de la banda que controla la droga en la isla, completamente original, y de sus secuaces; asimismo, el personaje de Candito el Rojo, presente en las novelas como amigo e informante de Conde, gana en importancia y se convierte en el punto de unión de las dos tramas: la policial y la de la vida personal de Conde.

Dicho esto, creo que hablar de Cuatro estaciones en La Habana en cuanto adaptación es hablar de una nueva obra que lee o interpreta su precedente literario, puesto que al cambiar el medio de expresión cambia el lenguaje; y, al variar tanto el medio como el autor y el contexto en el que se produce, también se modifica el discurso (Pérez Bowie, 2010: 24). En cuanto a la relación que mantiene con la obra literaria original, cabe decir que no es la vulgarización ni la parodia ni el cuestionamiento crítico; más bien se suma a la intención crítica del texto original rindiéndole, así, homenaje, y dialoga con él para profundizar en el subtexto, especialmente, en la visión que este da de la decadente y misteriosa ciudad de La Habana.

\section{Autorreferencia y autoconciencia}

Entre los elementos del texto literario que no han sido recuperados plenamente en las versiones audiovisuales, hay dos que son fundamentales en las novelas, y que, sin desaparecer, pasan a ocupar un lugar más discreto en estas últimas; me refiero a la reflexión sobre la propia literatura y a la conciencia del carácter ficcional de la creación artística. La discusión literaria, las citas, las alusiones a autores y obras e incluso los plagios son habituales en estas novelas en las que el protagonista, aunque es policía, persigue el sueño de ser escritor. En sus cavilaciones y en las conversaciones que mantiene 
con otros personajes, principalmente con el dramaturgo Alberto Marqués en Máscaras, Conde da cuenta de sus preferencias literarias (que son también las del autor); rechaza el tipo de literatura panfletaria impuesto por los dirigentes revolucionarios hasta prácticamente los años noventa; $\mathrm{y}$, a pesar de su pertenencia al bando de los represores, desprecia los abusos cometidos contra artistas e intelectuales en la década de los setenta por cuestiones relativas a la ideología y a la orientación sexual. Asimismo es evidente la carga metaficcional de unas novelas en las que constantemente se recuerda al lector que está frente a un producto de ficción artísticamente elaborado, ya no solo porque el protagonista desea escribir «historias escuálidas y conmovedoras como la de Esmé o los tormentos de los hermanos Glass»(1994: 90) e, incluso, porque se descubre como el narrador de la tetralogía paduriana al final de la cuarta novela (1998: 259), sino también porque el autor se cita a sí mismo e incluye discusiones sobre su propia obra en el cuerpo del texto. Recurriendo a la terminología utilizada por Pedro Javier Pardo, en el caso de las novelas tendríamos que hablar de «autorreferencia» -se habla de literatura desde la literatura- y de «autoconciencia»-se destaca su condición de artefacto literario(2015: 50-51).

En la película y en la miniserie, aunque estos dos aspectos no tienen la misma posición de importancia, sí poseen, al igual que en la obra literaria, un papel determinante para su interpretación. Es su caso, tanto las referencias a autores y a obras literarias como las conversaciones y las reflexiones de Conde sobre literatura se han reducido; no obstante, están presentes, sobre todo en los dos últimos capítulos de la miniserie; en el tercero, aparece Marqués y, gracias a sus conversaciones con Conde, este escribe, por fin, un relato del que no tenemos tanta información como en la novela; en el cuarto, la primera parte comienza con una imagen de la máquina de escribir sobre la mesa y con un aparato de radio que anuncia la inminente llegada de un potente huracán al Caribe. Tras la cabecera, aparece Conde subido a la barandilla de un balcón con los brazos abiertos en cruz, convocando la llegada del huracán mientras recita unos versos de José María Heredia; versos que aparecen como epígrafe de la cuarta novela: «Huracán, huracán, venir te siento». Al final de la segunda parte, coincidiendo con la irrupción del huracán en La Habana, Conde se sienta de nuevo a escribir con actitud determinada. El viento abre la ventana de su cuarto de par en par; este se levanta, aprecia con entusiasmo el vendaval, cierra los ojos y cierra la ventana, dando a entender con este gesto -igual que se hace notar en la novela- el final de la etapa en la que el sueño de la revolución era posible. Sin embargo, el final de la miniserie es bastante más abierto que el de la novela, porque no hay ese guiño del Conde narrador de la tetralogía que alerta al lector de que se halla ante un mundo de ficción; no sabemos qué es lo que este se sienta a escribir. Podemos decir, entonces, que tanto en la película como en la miniserie de Viscarret, hay, aunque rebajada, una reflexión sobre la literatura.

Asimismo, tanto en una como en otra hay señales claras de que existe una conciencia de su propia naturaleza ficcional. Recurriendo de nuevo a Pardo, en ambos medios audiovisuales, podemos hablar, por un lado, de un tipo de autoconciencia encubierta que linda con la autorreferencia, ya que no hay una mención explícita al mundo del cine o de la televisión pero sí hay marcadores que el espectador puede percibir dependiendo de su competencia metaficcional (2015: 65). En este caso concreto, me 
refiero a las marcas de género: película y miniserie adoptan una estética deudora del cine negro clásico, donde apenas sale el sol y donde son habituales los contrastes entre luces y sombras,los ambientes hostiles y las imágenes de crímenes, policías armados, persecuciones, registros, e interrogatorios. Ciertamente, por una cuestión de fidelidad al original, no hay ni demasiados tiros ni mucha sangre, elementos que están solo sugeridos mediante una sutil utilización del color rojo en la cabecera y en ciertas escenas. Por otro lado, existe otro tipo de autoconciencia encubierta, que consiste en la utilización de otros medios y que, por este motivo, puede llamarse «intermedial» (Pardo, 2015: 6869). Estaríamos hablando de una autoconciencia en la que la autorreferencia se oculta tras la referencia a otras artes. La más clara es la referencia a la literatura y a su naturaleza ficcional, que está presente en la película y en cada uno de los capítulos de la miniserie. En estos casos, Pardo propone hablar de «metaficción literaria en el cine» (2015: 69) y, dado el caso, podemos añadir, en la televisión. Pero en las dos versiones audiovisuales, igual que ocurre en las novelas, existe una tendencia a combinar elementos provenientes de distintas artes y medios de comunicación (pintura, música, prensa, radio, televisión, etc.). De entre ellos, destaca el recurso al documental y a la fotografía en varios capítulos de la miniserie, hecho que acentúa el carácter ficcional de la misma.

Concretamente, la primera parte del tercer capítulo, «Máscaras», comienza con una grabación de archivo histórico, no muy nítida por su antigüedad, que muestra, en blanco y negro, la plaza de la Revolución, en un Primero de Mayo (probablemente el de 1959), atestada de gente con banderas y pancartas. Lo curioso es que el discurso de Fidel Castro que se escucha de fondo es muy posterior a las imágenes. Las palabras referidas corresponden al «Mensaje a los estudiantes universitarios cubanos», pronunciado el 3 de septiembre de 2010 en la Universidad de La Habana, en el que Fidel rechaza la violencia ejercida contra cualquier país y contra cualquier ser humano, y, como tantas otras veces, exhorta al pueblo cubano a actuar como salvador en un conflicto que no le concierne: «Partimos de que ningún problema mundial debe resolverse por métodos de fuerza. Nadie tiene el derecho de usar la violencia contra ningún ser humano. Si no hacemos nada nadie se salvará. En esta, como en muchas luchas del pasado, es posible vencer» (Viscarret, 2016b; Castro, 2010). Esta distorsión temporal marca una discordancia entre los hechos reales y los discursos de la Revolución que condiciona la interpretación del capítulo, y que es uno de los mensajes en los que también insiste la novela.

Estas imágenes y este audio se intercalan con las imágenes del presente de la narración, en las que aparece la que será la víctima preparándose, más concretamente, travistiéndose, para el sacrificio. El objetivo de esta combinación de imágenes borrosas de la masa en un pasado glorioso, con un discurso de hace unos años cuya recepción dificultan las voces y la música, y con las imágenes nítidas que capturan el detalle del carmín en los labios, del rímel en las pestañas, del pendiente en la oreja de la víctima -Alexis- en 1989 problematiza la relación entre realidad y ficción con respecto a un tema que es ampliamente tratado en la novela pero poco explotado en la miniserie: la naturaleza del travesti. ¿Qué es más real, la imagen borrosa de un pueblo que soñaba construir al Hombre Nuevo, un discurso 
empecinado y a destiempo o un hombre vestido de mujer que reivindica su individualidad y su derecho a ser él mismo?

La segunda parte de este capítulo se cierra con un reportaje fotográfico en el que aparecen la policía interpelando a unos jóvenes, alguna que otra mirada indiscreta y travestis en su ambiente, naturales, sensuales, divertidos y provocativos. Este cierre aporta una mirada abierta y respetuosa hacia el mundo del travestismo y de la homosexualidad que intenta suplir la amplia discusión desarrollada en torno a él en la novela. También el capítulo titulado «Pasado perfecto» termina con un reportaje fotográfico en el que se muestran imágenes de infancia y juventud de un grupo de chicos. Aunque son fotos de momentos de un pasado real, estas intentan reemplazar una información que no ha podido darse de otro modo en la miniserie: la del pasado de Conde y sus amigos, felices jugando al béisbol en la calle o estudiando en la escuela, con los afiches de sus líderes políticos sobre las cabezas. Estas contrastan con el general tono de desencanto que transmiten los personajes en 1989, y especialmente con el abatimiento de Conde en la última escena.

Por último, la segunda parte del cuarto capítulo, «Paisaje de otoño», se cierra con la grabación de un huracán tropical real, que derriba casas, que encalla barcos y que anega plantaciones enteras. Las olas inmensas rebasan el Malecón e inundan las calles de La Habana. El reportaje viene, una vez más, a destacar el carácter ficcional de la miniserie. Pero, además, igual que en la novela, funciona como metáfora del final de una etapa de sacrificios, engaños y falsedades; es un huracán destructor y purificador al mismo tiempo. De esta forma se cierra una miniserie que empezaba con los vientos de cuaresma en la noche oscura de una ciudad caribeña; detalle muy apropiado que contribuye a elevar la poeticidad de esta versión audiovisual de las novelas de Padura.

\section{Visualidad de La Habana}

El tratamiento dado a la imagen, especialmente a la de la ciudad de La Habana, aumenta la poeticidad de la obra de Viscarret. En la obra literaria de Padura, la representación de La Habana, que es casi como un personaje más dentro del entramado dramático, tiene un peso fundamental; esta aparece caracterizada, desde el punto de vista crítico de Conde, por sus cicatrices, sus colores, sus sabores, sus sonidosy su clima. En opinión del escritor, Viscarret logra dar una visión íntima de la ciudad sin incidir en el tema de la ruina ni en el de la ciudad que se desintegra y sin adoptar una postura crítica (Padura, 2010). Efectivamente, el director se ocupa de reflejar el deterioro de las calles y los edificios y de insinuar su lado más oscuro y misterioso, pero, al mismo tiempo, consigue transmitir la imagen de un lugar todavía majestuoso donde la sorpresa puede estar a la vuelta de cualquier esquina.

Los lugares que se muestran en la película y en la miniserie son tanto de exteriores como de interiores. Por un lado aparecen calles y callejuelas de distintos barrios, unos más populares, más o menos deteriorados, más o menos transitados, y otros más elegantes y cuidados. Se distinguen,por ejemplo, calles de la Habana Vieja, de Centro Habana y del Vedado, pero también carreteras y caminos de tierra que llevan hasta elegantes mansiones alejadas del bullicio. Además se detiene en lugares 
emblemáticos como el Paseo del Prado, lugar de por excelencia del ambiente homosexual habanero; la esquina 23 y 12 del Vedado, espacio para la recreación, en el que en su día se celebraron importantes manifestaciones revolucionarias; el enigmático Bosque de La Habana, con su exuberante vegetación tropical; o el puerto, con su tráfico escaso. Entre los espacios de interior, se encuentran casas viejas, desvencijadas y austeras y mansiones pulcras, excesivamente recargadas de cuadros y de mobiliario caros, con espectaculares jardines.También se utilizan como escenario lugares con un significado especial porque forman parte de la vida de Conde (y de Padura), como el Preuniversitario de La Víbora, donde ambos realizaron sus estudios.

Las imágenes de los exteriores de La Habana no siempre coinciden con los mencionados en las novelas, pero la manera en la que estos aparecen presentados proporciona un efecto de laberinto intrincado, y muestra, como indica Padura, «cómo La Habana en el fondo es como un collage de texturas, de casas de diferentes épocas y estilos» (Telemadrid, 2016). Esto se logra principalmente utilizando un ángulo visual de plano aéreo o cenital sobre la ciudad, gracias al que se observan azoteas con múltiples divisiones, estrechas y laberínticas callejuelas y vías más amplias con el tráfico de esos antiguos coches de los años treinta, cuarenta o cincuenta de origen americano y de los años sesenta o setenta de origen soviético, que van dejando un impresionante reguero de humo contaminante. El mismo contraste de formas y estilos puede verse a pie de calle mientras Conde camina y entra en callejones llenos de recovecos, pasillos, escaleras y viviendas con una planificación desordenada, o cuando va en el coche y, desde él, se enfocan edificios coloniales, de la etapa republicana o de la revolucionaria. De vez en cuando se muestran también planos contrapicados que captan el detalle del denso humo saliendo de un tubo de escape o una panorámica de La Habana, que resulta magnificada por su posición elevada.

Según el encuadre de la cámara, pueden verse planos panorámicos generales de la urbe tomados desde distintos puntos, en los que casi siempre destacan por su altura el Capitolio en la Habana Vieja, el hospital Hermanos Ameijeiras en Centro Habana y los bloques de viviendas construidos en el Vedado. Estas panorámicas pueden ser planos generales, un poco más cercanos, en el que se aprecian mejor los detalles. Lo mismo ocurre con el encuadre de los personajes. Es interesante destacar los primeros planos, que permiten captar la gestualidad del cuerpo y del rostro y, especialmente, los planos detalle, como los utilizados para presentar a Alexis al inicio de «Máscaras» mientras se viste de Electra Garrigó, personaje de la pieza teatral de Virgilio Piñera; o mientras camina por el Malecón y solo se ven sus piernas con los zapatos rojos de tacón y el vestido también rojo. Estos planos detalle, acompañados de una utilización particular del color y de la música, revelan sensaciones, intenciones y sentimientos. En este caso concreto, dejan notar la delicadeza, sensibilidad, elegancia y decisión de Alexis, disponiéndose a avanzar hacia una muerte segura; al mismo tiempo, resultan inquietantes, al destacar el color rojo, al sonar de fondo una música religiosa como el «Requiem Agnus Dei» de Gabriel Fauré y al aparecer mezclados con las imágenes del documental y con el discurso de Fidel. Todos estos elementos enriquecen estéticamente el capítuloy condicionan su ambiente. 
En cuanto al punto de vista que adopta la cámara, resultan curiosos los momentos en los que esta reproduce una escena habitual en las calles habaneras: como si estuviera colocada en el balcón de un edificio, la cámara adopta la mirada de un voyeur que intenta espiar a través de las ventanas o que observa a la gente que, a su vez, mira a la calle desde sus balcones sin prisa, entretenida, haciendo notar un tiempo detenido; aquí, la música tiene un papel fundamental, ya que son sones cubanos lo que se escucha de fondo, subrayando así la cubanidad de esta imagen («Máscaras», Parte II). Este recurso es necesario para suplir toda la información contenida en las novelas - gran parte de ella, referida por Conde- y elidida en la película y en la miniserie. También el avance pausado de la cámara -que, a veces, alcanza directamente la cámara lenta- o el movimiento circular que esta realiza cuando, por ejemplo, Conde llega al Preuniversitario de la Víbora (Vientos de La Habana, Parte I) denotan un tiempo detenido; prácticamente, irreal.

El recurso al contraste entre luces y sombras y el uso de determinados colores matizan el sentido de las imágenes captadas por la cámara y convierten el espacio de la ciudad en un verdadero escenario de cine negro. En primer lugar, en la película y en la miniserie prima la oscuridad. La mayor parte de las escenas son nocturnas.En ellas, La Habana aparece como una masa oscura apenas iluminada por unas pocas luces mal repartidas. Las escenas adquieren una tonalidad grisácea que hace que el contraste lumínico recuerde, a veces, a las películas clásicas en blanco y negro. La utilización del contraluz da protagonismo a las sombras, que se colocan y se mueven estratégicamente en un laberinto de calles mal iluminadas en las que solo se ve con nitidez el caótico cableado que las cruza de lado a lado. Tanto en el interior como en el exterior de los edificios se juega con las sombras que proyectan los objetos, particularmente, con las líneas gruesas que dibujan las rejas y las persianas, que sirven para poner en duda la credibilidad de las personas que están tras ellas o de la información que allí se discute. Algunos espacios interiores aparecen siempre matizados con la tonalidad gris, independientemente de si es de noche o de día, como sucede en la Central de policía, lugar por excelencia del engaño y de la mentira, no solo porque en ella, como se descubre en la miniserie, se sostiene un gigantesco entramado de corrupción y espionaje, sino porque esa Central de policía es, igual que en las novelas, un espacio completamente inventado para que el mundo de ficción de Conde pueda funcionar.

Tratándose de una ciudad caribeña, no podía faltar el sol; sin embargo, su presencia no aporta claridad a la escena. En las escenas diurnas de calle, si brilla el sol, lo hace de tal manera que difumina la imagen. En estos casos, la imagen toma una coloración tenue de tonos ocres que dota al conjunto de una atmosfera misteriosa, inquietante e irreal. En las escenas de interior, casi siempre en penumbra, la fuente de luz suele ser artificial e insuficiente, lo que pone de relieve la escasez de recursos en la que viven los personajes, e incluso los refugios que han tenido que crear para controlar su frustración, como sucede, a mi juicio, en el interior de la Iglesia. Si el sol entra por las ventanas es para difuminar la imagen y para darle una tonalidad ocre que acentúa la sensación de angustia, de tiempo detenido y de falsedad. Esto es lo que pasa, por ejemplo, en la casa de Karina («Vientos de La Habana», Parte II) cuando esta le confiesa a Conde la verdad. En ese momento, ella se coloca frente a la ventana y la luz difumina su imagen, de la que destaca el color rojizo del cabello, mostrando, así, que su historia con 
Conde no ha sido más que un ensueño. Entonces, Conde, a contraluz, es solo una silueta captada de espaldas, que recibe una información aplastante. En la casa de Marqués («Máscaras»), las cortinas rojizas atenúan el paso de la luz, señalando de este modo el aislamiento en el que vive el personaje, antiguamente represaliado por el régimen. Las cortinas indican que -como ocurre en la novela- la decisión de mantener el aislamiento es, en la actualidad, personal. En este espacio hay, no obstante, un juego con el reflejo de los espejos muy sugerente, ya que en este capítulo se abordan temas como el del travestismo y el de la gran mascarada que asume el país al completo en el proceso revolucionario.

Entre el gris y el ocre destacan solo algunos colores, estratégicamente utilizados. Me refiero al verde, que destaca la vegetación tropical; al azul, que potencia la presencia del mar por todas partes; y al rojo, que reproduce el color de la sangre y del crimen. Estos dos últimos son especialmente simbólicos en «Máscaras», donde el azul tiñe la bata de Marqués en un claro homenaje a Virgilio Piñera, quien reflexiona en profundidad sobre la condición de insularidad y de aislamiento que afecta al pueblo cubano; y donde el rojo, además de contribuir a la recreación de la escena de un crimen en el que, en realidad, no hay sangre, trae a la memoria al personaje y la obra de este escritor: Electra Garrigó. Al ambiente sombrío y negro de estas escenas, se suma elhumo denso que sale de los cigarrillos y de los tubos de escape de los automóviles inundándolo todo y acentuando el ambiente de misterio. A falta de humo, es la bruma espesala que se apodera de la escena produciendo el mismo efecto.

Finalmente, la música viene a completar el sentido de la imagen. Su presencia es prácticamente continua, y matiza con precisión el sentido de cada suceso. Por una parte, está la música original, a cargo de Mikel Salas, creada específicamente para la película y para la miniserie. Acudiendo al jazz clásico, esta crea un ambiente perfecto para una obra de género negro, gracias a los cambios de tempo y a la tensión que añaden las cuerdas de los violines con sonidos agudos y figuraciones rápidas. La inclusión de sones marca la identidad de una música que, si bien sirve para destacar el género de la obra, es propiamente cubana. Por otra parte, los momentos claves se acompañan de piezas concretas. Cuando Conde y sus amigos se reúnen para beber cantidades ingentes de ron, para conversar sobre sus vidas y su destino y para engullir banquetes imposibles de imaginar en Cuba, se escucha siempre la Creedence Clearwater Revival. Igual que ocurre en las novelas, la Creedence tiene un valor particular para los personajes, así como para los miembros de la generación de Padura, porque es lo que ellos preferían escuchar en su juventud, a pesar de las recomendaciones y prohibiciones del régimen. Es, para ellos, una seña de identidad. Por eso, esta escena, con esta música concreta, se repite en la película y en la miniserie.

Como no puedo detenerme a analizar la música que aparece a lo largo de ellas, me fijaré solo en las significativas piezas que se escuchan en «Máscaras». En este capítulo, la canción escogida de la Creedence no podía ser más oportuna para dar relevancia a la muerte de un ser incomprendido en el Bosque de La Habana: «Born on the Bayou». Anteriormente, mencioné el «Requiem Agnus Dei» de Fauré, que acompaña a Alexis, travestido, hacia una muerte planeada teniendo en cuenta la bíblica Transfiguración de Cristo. Además, se escucha el aria «Vissi d'arte» para soprano de la ópera Tosca 
de Giacomo Puccini en el momento en el que la esposa del amante de Alexis descubre que su matrimonio es una farsa. Su elección es bastante adecuada si pensamos en la suerte del marido, un pintor homosexual que, hasta ese momento, ha vivido en una gran mentira. En último lugar, el reportaje fotográfico de los travestis viene acompañado de un bolero muy significativo ( $\sin$ atribución de autor), que habla del amor de una figura iluminada, encontrado y perdido en La Habana.

Por último, creo importante referirme a la canción «Vivir al borde» de Andrés Levin, Claudia Brant y Fernando Osorio, interpretada por los Hanky Punky's Feat, que se escucha en la cabecera de la serie. Esta habla de «una vida sucia, un camino oscuro y la noche larga que nunca conduce a lugar seguro», y se adapta perfectamente al género negro gracias a la tensión generada con las cuerdas de la guitarra y la percusión. En realidad, la cabera en su totalidad es un producto muy elaborado que anuncia ya el género de la serie con las imágenes de una Habana oscura, envuelta en una gran humareda, con los contrastes de luces y sombras y con el letrero del título teñido de rojo.

Para concluir, me gustaría destacar la calidad de la película y, sobre todo, de la miniserie creadas por Viscarret, quien demuestra que, ya sea para el cine o para la televisión, ese medio tan denostado, es posible presentar productos no solo interesantes por el contenido, sino también trabajados desde un punto de vista estético. Si bien su obra parte de la adaptación de las cuatro exitosas novelas de Padura mencionadas, el resultado es un producto nuevo que rinde homenaje a su precedente, y que entabla un diálogo con él sobre la realidad cubana y sobre su posible representación artística. Si las novelas son cinematográficas y profundamente literarias, autorreflexivas y autoconscientes, la película y la miniserie también hablan de literatura y se muestran conscientes de su estatuto de ficción. La lograda visualidad de La Habana que nos ofrecen, en la que entra en juego el lenguaje de otras artes como la fotografía, la pintura y la música, son prueba de su plasticidad y de su poeticidad.

\section{Referencias bibliográficas}

Castro, F. (2010): «Mensaje a los estudiantes universitarios cubanos», Cubadebate, en http://www.cubadebate.cu/especiales/2010/09/03/mensaje-a-los-estudiantes-universitarios-decuba/\#.WW7S0elpzIU (última consulta, 18-6-2017).

ColmeIRo, J. (1994): La novela policiaca española: teoría e historia crítica. Barcelona, Anthropos.

PADURA, L. (1991): Pasado Perfecto. Barcelona, Tusquets, 2ª ed., 2007.

(1994): Vientos de Cuaresma. Barcelona, Tusquets, $2^{\text {a }}$ ed., 2007.

(1997): Máscaras. Barcelona, Tusquets, $4^{\mathrm{a}}$ ed., 2007.

(1998): Paisaje de otoño. Barcelona, Tusquets, $3^{\mathrm{a}}$ ed.,2009.

(2016): «Conversación "Vientos de La Habana", de la literatura al cine», con Leonardo Padura,

Lucía López Coll y Félix Viscarret», Casa América, 30-9-2016, en https://www.youtube.com/ watch?v=dXPSCYuj0_Q (última consulta, 12-6-2017). 
360 Tropelías. Revista de Teoría de la Literatura y Literatura Comparada, número extraordinario 2 (2017) Paula García Talaván

PARdo García, P. J. (2015): «Hacia una teoría de la reflexividad fílmica: la autoconciencia de la literatura al cine», en J. A. PÉREZ BOWIE y P. J. PARDO GARCÍA, eds., Transescrituras audiovisuales. Madrid, Sial Pigmalion, 2015, pp. 47-94.

PÉREZ BowIE, J. A. (2008): Leer el cine: la teoría literaria en la teoría cinematográfica. Salamanca, Ediciones Universidad de Salamanca.

- (2010): Reescrituras fílmicas: nuevos territorios de la adaptación. Salamanca, Ediciones Universidad de Salamanca.

SCOLARI, C. A. (2013): Narrativa transmedia: cuando todos los medios cuentan. Barcelona, Deusto.

TELEMADRID.ES (2016): «Llega este viernes a la gran pantalla Vientos de la Habana», Telemadrid.es, en http://www.telemadrid.es/noticias/cultura/noticia/llega-este-viernes-la-gran-pantalla-vientosde-la-habana (última consulta, 18-6-2017).

VisCARRET, F. (2016a): Vientos de La Habana. España, Cuba, Alemania. Tornasol Films/Hernández y Fernández PC/ Mistery Producciones AIE.

- (2016b): Cuatro estaciones en La Habana. España, Cuba, Alemania. Tornasol Films. 